\title{
Resource Letter SRT 1 on Special Relativity Theory
}

\section{Citation}

Holton, Gerald. 1962. Resource Letter SRT 1 on Special Relativity Theory. American Journal of Physics 30, 462. http://doi.org/10.1119/1.1942062

\section{Permanent link}

http://nrs.harvard.edu/urn-3:HUL.InstRepos:37902458

\section{Terms of Use}

This article was downloaded from Harvard University's DASH repository, and is made available under the terms and conditions applicable to Other Posted Material, as set forth at http:// nrs.harvard.edu/urn-3:HUL.InstRepos:dash.current.terms-of-use\#LAA

\section{Share Your Story}

The Harvard community has made this article openly available.

Please share how this access benefits you. Submit a story.

Accessibility 


\title{
NOTES AND DISCUSSION
}

\section{Resource Letter SRT 1 on Special Relativity Theory $\dagger$}

\author{
(January 1962)
}

\begin{abstract}
Prepared by Gerald Holton, Department of Physics, Harvard University, at the request of the Commission on College Physics.

This is one in a series of Resource Letters on different topics, intended to guide college physicists to some of the literature and other teaching aids (e.g., films, educational apparatus) that may help them to improve course contents in specified fields of physics. No Resource Letter is meant to be exhaustive and complete; in time, there may be more than one on each of the main subjects of interest. Your suggestions and comments will be welcomed.

Terminology: The letter $E$ after the consecutive item number (e.g., 2.E). means the items should be mainly useful for elementary (freshman liberal arts through sophomore physics) courses; the suffix $I$ (e.g., 7.I) indicates intermediate (junior, senior) courses; and the suffix $A$ indicates advanced (senior, graduate) courses. An asterisk (*) signals items particularly recommended for introductory study.

Additional copies: Available from American Institute of Physics, 335 East 45 Street, New York 17, New York. When ordering, request Resource Letter SRT-1, and enclose a stamped return envelope.
\end{abstract}

\section{INTRODUCTION}

Over the next few years, a good deal more SRT (special relativity theory) will find its way into introductory and intermediate college physics courses. With this aim in view, plans for writing and for equipment development are at last under way in several colleges. Instructors everywhere should seriously think now of participating in this effort, or at least of getting themselves and their classes ready to use more teaching material on SRT. For this purpose, the present Resource Letter, the first one on this subject, takes a selective look at certain helpful resources that are now available on some of the main topics in SRT. It is intended to be used by instructors, but may also be useful to students doing a course essay on a specific subtopic.

The instructor interested in introducing more SRT in his course faces at least five problems: (1) The amount of publication is immense, but its usefulness for the classroom is usually low. (2) Very little equipment or other aids exist to help the man behind the empty lecture bench make his points. (3) Enough time must be made for SRT in the course if it is to have any meaning to the student. (4) A clear line of argument for getting through SRT (and possibly to introductory GRT) must be selected from among several possibilities. (5) Enough integration with other topics (e.g., QM, nuclear physics) must be achieved to do justice to the full power of SRT.

This Resource Letter should help to deal with the first of these problems, that of the huge bulk of publications. No doubt the best way to begin using the Resource Letter is to find among the next eight sections one on which to concentrate.

\section{Ir, HOOKS: SOURCES AND TEXT'}

Seven books are so good, so basic, and so widely used that nothing new need be said about them. They are, so to speak, double-starred, and must be nearby and accessible if one teaches SRT: A. S. Eddington, The Mathematical Theory of Relativity; A. EINSTEIN, Relativity, the Special and General Theory; A. EInstein, The Meaning of Relativity; M. von LAUE, Die Relativitätstheorie; C. M $\phi$ LLER, The Theory of Relativity; R. C. Tolman, Relativity, Thermodynamics, and Cosmology; H. WEYL, Space, Time, Matter.

*1.I The Principle of Relativity. A Collection of Original Memoirs on the Special and General Theory of Relativity. A. Einstein, H. A. LoRentz, $H$. Minkowski, AND H. Weyl. Notes by A. Sommerfeld. (Dover Publications, Inc., New York, 1958), 216 pp. (Reprint of 1923 translation.) Paperback. The translation of Einstein's basic paper of 1905 in this edition is much better than another translation prepared in 1920 by Saha and Bose. Among detailed analyses and critiques of content of this paper, see R. Dugas (item 29) and L. Silberstein (item 39).

*2.E La Cinématique relativiste. H. Arzelik̀s. (Gauthier-Villars, Paris, 1955), 228 pp. Among the most careful and readable works, with extensive bibliography for each chapter. This book and item 3 should be a major new resource for instructors.

*3.I La Dynamique relativiste et ses applications. H. Arzeliès. (Gauthier-Villars, Paris.) Vol. I, 1957, 304 pp.; Vol. II, 1959, 451 pp. See item 2.

*4.E Einstein's Theory of Relativity. MAX BoRN. (E. P. Dutton and Company, Inc., New York, 1924), 293 pp. Without doubt the best elementary account. 
Thoroughly works out everything, from how to plot graphs through Maxwell, Minkowski, to GRT, with very few rabbits being pulled out of the hat. Leaving it so long out of print is a black mark against the world of publishing, but a paperback edition is now said to be planned.

5.I La Théorie de la relativité restreinte. O. Costa de Beauregard. (Masson et Cie, Paris, 1949), 174 pp. Bibliography develops and uses tensors from the beginning.

*6. I Introduction to the Theory of Relativity. P. G. Bergmann. (Prentice-Hall, Englewood Cliffs, New Jersey, 1942), 287 pp. Long a standard text. Introduces tensor calculus but uses it sparingly in Part I (SRT). With problemis. Bergmann has been announced to have written the section on SRT in the new Handbuch der Physik, $I V$, which may turn out to be useful in place of a new edition of this book.

7.I Relativity Physics. W. H. McCrea. (Methuen, London, and John Wiley \& Sons, Inc., New York, 1954), 4th ed., 87 pp. Useful condensation of the essentials, with footnotes (though mostly only to work before 1936). Herbert Dingle's elementary companion monograph, The Special Theory of Relativity (Methuen, London, and John Wiley \& Sons, Inc., New York, 1940), 91 pp., is said by Dingle to "serve as an introduction" to McCrea's.

*8.I Theory of Relativity. W. Pauli. (Pergamon Press, New York, London, 1958), revised ed., 241 pp. Originally "a complete review of the whole literature on relativity theory" up to 1921 , it was brought up to date by 26 supplementary pages written in 1956 (though these are mostly on GRT). This book still functions as a major Handbuch for its field.

9.I Mathematics of Relativity. G. Y. RaINICH. (John Wiley \& Sons, Inc., New York, 1950), 173 pp. "Old Physics," "New Geometry," "Special Relativity," "Curved Space," and "General Relativity." Aims to bring "complete clarity" to presentations of SRT "by stressing mathematical aspect of the subject," introducing the more sophisticated tools step by step. Exercises.

*10.I Special Relativity. W. RindLer. (Oliver and Boyd, Edinburgh and London; Interscience Publishers, Inc., New York, 1960), 179 pp. A concise, well thought-out book; assumes only elementary calculus and vector theory, develops tensors as needed. $\mathrm{Nu}$ merous exercises. Proceeds via Lorentz transformation, kinematics, optics, tensors, mechanics of mass points, electrodynamics.

*11.I Special Relativity for Physicists. G. STEPHENson and C. W. Kilmister. (Longmans Green and Company, London and New York, 1958), 108 pp. Short but thorough. Written particularly for the experimental physicist, with a large number of specific applications. No tensor calculus. Short bibliographies.

12.I Les Principes de la théorie électromagnétique et de la relativité. Marie-Antoinette Tonnelat. (Masson et Cie, Paris, 1959), 394 pp. Clearly writ- ten, orderly, with full derivations, descriptions of experiments, and references to original papers. Part I, Electromagnetic Theory. Part II, SRT. Part III, GRT.

13.A Spezielle Relativitätstheorie. Acrimles PapapeTrou. (VEB Deutscher Verlag der Wissenschaften, Berlin, 1955), 170 pp. Two chapters (LT and Minkowski, dynamics of mass point) without tensors; three (electrodynamics, mechanics of continua, conservation laws) with tensors.

14.A Relativity: The Special Theory. J. L. Synge. (North-Holland Publishing Company, Amsterdam, 1956), 450 pp. ". . . the essentials of relativity from the Minkowskian point of view. . . My ambition has been to make space-time a real workshop for physicists, and not a museum visited occasionally with a feeling of awe." Hence original and stimulating. Bibliography. See also his similar but short treatment, "Relativistic Dynamics," in Vol. III, Part I (pp. 198-225) of Handbuch der Physik, S. Flügge, editor (Springer-Verlag, Berlin, 1960). Extensive bibliography of books on mechanics which treat SRT,

\section{BOOKS: POPUIAR}

15.E Space and Time. EmILe Borel. (Dover Publications, Inc., New York, 1960.) Original publication, 1922. 230 pp. Paperback. Still a useful, elementary book.

16.E La Relativité. Paul Counerc. (Presses Universitaires de France, Paris, 1958), 136 pp. No. 37 in scries "Que sais-je?" Paperback. A translation of this fine book has been arranged.

17.E Readable Relativity. Clement V. Durell. (G. Bell and Sons, London, 1926, and Harper and Brothers, New York, 1960, TB 530), 146 pp. Paperback. A passion for Lewis Carroll is offset by straightforward approach and exercises.

18.E Space, Time, and Gravitation. A. S. Eddington. (Harper and Brothers, New York, 1959, TB 510.) Reprint of 1920 edition. 213 pp. Paperback. Mostly on GRT.

*19.E The Evolution of Physics. Albert Einstein AND LeOpold INFELd. (Simon and Schuster, Inc., New York, 1938), 319 pp. A classic, now also in paperback.

*20.E Ideas and Opinions. Albert Einstein. (Crown Publishers, Inc., New York, 1954), 377 pp. Paperback. The best general collection of Einstein's essays. Part 5 is "Contributions to Science."

21.E What is Relativity? L. D. LANDAU AND G. B. Rumer. (Oliver and Boyd, Edinburgh and London, 1960). Translation of 1959 book. 64 pp. Paperback. A “lighthearted presentation," very qualitative.

22.E The Einstein Theory of Relativity. LILLIAN R. LIEBER. (Reinhart and Company, New York, 1945), 324 pp. Surprisingly sophisticated.

23.E Die Idee der Relativitätstheorie. HaNs ThIRRING. (Springer-Verlag, Vienna, 1948), 3rd ed. 168 pp. Paperback. Qualitative only. 
Note: See also M. Born, item 4, and Einstein, Relativity, the Special and General Theory.

\section{BOOK CHAPTERS}

A few introductory general texts and most intermediate-level general texts have a section on SRT. Necessarily, most of these sections are rather similar to one another. The following list contains mostly recent, largely intermediate-level books that have been selected as being among those that it would be profitable to look through, particularly for illustrations and problems.

24.E Principles of Modern Physics. A. P. French. (John Wiley \& Sons, Inc, New York, 1958), Chapter 6, pp. 137-173, "Relativity," emphasizes experiments and graphical presentations.

25.E The Basic Concepts of Physics. C. W. Sherwin, (Holt, Rinehart, and Winston, Inc., New York, 1961), Chapter 4, pp. 82-151, "Relativity," is a refreshing discussion using ingenious little drawings.

26.E Physics of the Atom. M. Russell WeHr AND James A. Richards, Jr. (Addison-Wesley Publishing Company, Reading, Massachusetts, 1960), Chapter 5, pp. 111-145. With simple, worked-out examples and 27 problems.

27.E Elementary Modern Physics. Richard T. WeIdNER ANd Robert L. Sells. (Allyn and Bacon, Inc., Boston, 1960), Chapter 2, pp. 43-86, "The Theory of Special Relativity." Patiently carried out; 40 problems.

28.I Theorie der Elektrizität. Band II. R. BECKER. (B. G. Teubner, Leipzig, Germany, 1933), 6th ed, $400 \mathrm{pp}$. Useful discussion of optical experiments, pp. 255-265, and "Die Mathematischen Hilfsmittel der Relativitätstheorie," pp. 282-296.

29.I A History of Mechanics. René Dugas. (Editions du Griffon, Neuchatel, Switzerland, and Central Book Company, New York, 1955), Part 5, Chapter 1, pp. 463-501, "Special Relativity." Despite a poor translation, this is an interesting analysis of the early work on SRT by Poincaré, Einstein, Minkowski, and Painlevé.

30.I Classical Mechanics. Herbert Goldstein. (Addison-Wesley Publishing Company, Inc., Reading, Massachusetts, 1950), 399 pp. Chapter 6, pp. 185-214, "Special Relativity in Classical Mechanics," a very clear treatment. 14 exercises.

31.I Principles of Modern Physics. Ronert B. LeIGHToN. (McGraw-Hill Book Company, Inc., New York, 1959), Chapter 1, pp. 1-56, "The Theory of Relativity." Brief but thorough. Simple tensor treatment. 86 exercises.

32.I Introduction to Modern Physics. F. K. RichtMYer, E. H. KenNard, and T. LaURITSEn, (McGraw-Hill Book Company, Inc., New York, 1955), 5th ed, 666 pp. Chapter 2, pp. 49-76, "The Theory of Relativity," in briefest compass.

33.A The Theory of Space, Time, and Gravitation. V. Fock. (Pergamon Press, London and New York, 1959), 411 pp. "The main purpose of this book was to develop the theory of gravitation from a new point of view," but even Chapter 1, on the special theory of relativity, is stimulatingly different from usual treatments.

34.A A History of the Theories of Aether and Electricity. Vol. II. The Modern Theories, 1900-1926. Sir Edmund Whittaker. (Philosophical Library, Inc., New York, 1954). (Also Harper Torchbook TB 532). Chapter II, "The Relativity Theory of Poincaré and Lorentz," is a useful, brief account of the development of ideas up to Schrödinger's formulation of Minkowski's energy tensor. Copious citations in footnotes serve well for finding original papers. The bias indicated in the title of the chapter is analyzed in G. Holton, "On the Origins of the Special Theory of Relativity," Am. J. Phys, 28, 627636 (1960). See also Vol. I, subtitled The Classical Theories (Harper Torchbook TB 531), Chapter XIII, "Classical Theory in the Age of Lorentz."

35.I "Relativity and Electrodynamics." W. F. G. Swank. Revs. Modern Phys. 2, 243-304 (1930). Listed here because it is still better than many book chapters. A thoughtful and well-written review-introduction to SRT stands up surprisingly well after 32 years.

Note: Useful chapters dealing with special topics exist also in other general texts such as Panofsky-Phillips (item 44); Shankland (item 36) ; R. B. Lindsay and H. Margenau, Foundations of Physics; W. Band, Introduction to Mathematical Physics; and A. Sommerfeld, Lectures on Theoretical Physics.

\section{SELECTED EXPEHIMENTAL WORK}

The fundamental significance of SRT does not depend on any one of the many experiments to "prove" SRT. Still, the larger part of contemporary physics, from spectroscopy to accelerator design, is concerned with experiments and theoretical arguments that do rest at some point on SRT. For introductory purposes, one may well discuss a few experiments, one or two each from, say, optics and particle dynamics.

It will be helpful to keep in mind a classification of the various experiments having a bearing on SRT, and to be aware of their chronological sequence. One such scheme (based in part on a suggestion by D. L. Livesey) follows here. In searching for more complete listings of original papers, see the bibliographical citation in Whittaker (item 34), Pauli (item 8), Arzeliès (items 2, 3), von Laue's Relativitätstheorie, Thirring (item 38). A magnificent listing of all work prior to 1924, ordered by author's name as well as chronologically, is Bibliographie de la relativité, Maurice Lecat (Lamertin, Brussels, 1924).

Aether-Drag in Dense Media: (a) Convection effects (e.g., Arago, 1818; Fizeau, 1859; MM, 1886; Zeeman, 1914). (b) Null experiments (Hoek, 1868; Airy, 1871). (c) Drag by large bodies (Lodge, 1893; Michelson, 1897). 
Aether-Drift Experiments (Air or Vacuum): (a) First-order effects (Cedarholm et al., 1958). (b) Second-order effects (Michelson, 1881; MM, 1887; Kennedy-Thorndike, 1932; Essen, 1955). (c) Indirect aether-drift effects (Double refraction: Rayleigh, 1902; Brace, 1904. Torque on condensor: Trouton-Nobel, 1903; Chase, 1926-27; Tomaschek, 1925-27).

Effects of Moving Source or Mirror: (de Sitter, 1913; Michelson, 1913; Majorana, 1917-19; Tomaschek, 1924).

Rotating Frame Experiments: (Sagnac, 1913-14; Michelson, 1925 ; Ditchburn-Heavens, 1952).

Time Dilation: (a) Transverse Doppler effect (IvesStilwell, 1938, 1941; Otting, 1939) (b) Lifetime of mesons (Rossi-Hall, 1941; Durbin-Loar-Havens, 1952).

Dynamics of High-Speed Particles: (a) Deflection of electrons (Bucherer, 1908-09; Neumann, 1914; GuyeLavanchy, 1916; Rogers et al., 1940). (b) Fine structure of $H$ lines (Sommerfeld, 1916; Glitcher, 1917; Williams, 1938). (c) Scattering (Compton effect: Compton, 1923. Electron-electron scattering: Champion, 1932 ; Joliot, 1935 ; Leprince-Ringuet, 1936. Proton-proton scattering: Chamberlain-Segré, 1952).

Mass-Energy Equivalence in Nuclear Physics: (a) Mass defect (Cockcroft-Walton, 1932; Bainbridge, 1933). (b) Pair production (Anderson, 1933; Blackett and Ochialini, 1933). (c) Annihilation radiation (Klemperer, 1934; DuMond et al., 1949). (d) Decay schemes of elementary particles (Marshak, 1955). (e) Other (e.g., Linac limiting velocity, Mössbauer effect).

\section{A. General Surveys}

*36.I Atomic and Nuclear Physics. Robert S. Shan KLAND. (The Macmillan Company, New York, 1960), 2nd ed., 665 pp. A clear, well-illustrated and experimentally oriented book, selected here as representative of the best ones for the purposes of this. Resource Letter. References to original papers. Among experiments discussed are some on fine structure of spectral lines, electron mass variation with velocity, beta-ray spectra, synchrocyclotron design, meson production, binding energies, fission and fusion reactions, nucleon scattering, and lifetime of mesons.

37.I "Quelques vérifications expérimentales récentes de la théorie de la relativité restreinte." RoBERT Lennuier. Rev. Sci. (Paris) 85, 740-748 (1947). A good, brief survey, with main results. The partial list, showing size of field to chose from, includes fine structure of hydrogen lines, Ives-Stilwell experiment, lifetime of mesons measured by Rossi et al., effects of particle speed on inertia and on scattering angle (details of Leprince-Ringuet's work), and $Q$ values.

38.I Handbuch der Physik. Band XII: Theorien der Elektrizität. (Verlag Julius Springer, Berlin, 1927), 564 pp. Chapter 3, pp. 245-348. "Elektrodynamik bewegter Körper and Spezielle Relativitätstheorie," by $H$. Thirring. A useful summary, with accent on experimental results. Full bibliographical notes.

39.I The Theory of Relativity. L. SildersteIn. (Macmillan and Company, Ltd., London, 1924), 563 pp. Still useful, both for detailed derivations and accounts of experiments.

40.I Kritik und Fortbildung der Relativitätstheorie. KarL SAPPER, editor. (Akademische Druck-u. Verlagsanstalt, Graz, Austria, 1958), 283 pp. Essays by Benedicks, Giese, Golling, Grünbaum, Mohorovičić, Moon, Sapper, Spencer, Tonini, Wenzl, and Zinsen. "Agreement on the need for rejecting dogmatism unites the otherwise widely differing points of view of the authors." Chosen here to stand for the many books critical of Einstein's RT; contains attacks on the usual interpretation of experimental results and on "the dangerous influence of positivism in physics."

Note: In addition, surveys of the main experiments are given in some of the more general books, particularly Arzeliès (items 2, 3), Tonnelat (item 12), PanofskyPhillips (item 44), Stephenson and Kilmister (item 11 ), and Rindler (item 10).

\section{B. Optical Experiments: Reviews}

41.E Grundversuche der Physik in hịstorischer Darstellung. Carl Ramsauer. (Springer-Verlag, Berlin, 1953), 189 pp. This very useful book contains (pp. 63-70) quantitative descriptions of the main experiments by Roemer, Fizeau, and Foucault. Bibliography.

42.E Historic Researches. Chapters in the History of Physical and Chemical Discovery. T. W. CHALMERs. (Charles Scribner's Sons, New York, 1952), Chapter 4, pp. 64-83, "The Ether Drift Experiments," describes several experiments qualitatively. Slightly marred by somewhat naive philosophizing.

43.E A Source Book in Physics. W. F. MagIE. (McGraw-Hill Book Company, Inc., New York, 1935). Brief excerpts from publications on velocity of light measurements by Michelson and Morley (1887; pp. 369-377), as well as by Roemer, Bradley, Fizeau, and Foucault (pp. 335-345).

*44.I Classical Electricity and Magnetism. Wolfgang K. H. Panofsky and Melba Phillips. (AddisonWesley Publishing Company, Inc., Reading, Massachusetts, 1955), 400 pp. Chapter 14, pp. 230-242, "The Experimental Basis for the Theory of Special Relativity," is as pithy and useful a treatment as exists. Includes the table comparing trials of the MM experiment, from R. S. Shankland et al. (item 53) and a discussion of Kennedy-Thorndike experiment. Bibliographies to original experimental papers. (See also the chapters from 15 on-for other valuable teaching resources on SRT.)

45.A "Postulate versus Observation in the Special Theory of Relativity." H. P. Robertson. Revs. Modern Phys. 21, 378-382 (1949). The task set here is that of "replacing, so far as possible, Einstein's relativity postulate by facts drawn from experience." This is done by discussion of MM, Kennedy-Thorndike, and Ives-Stilwell experiments. 


\section{Optical Experiments: Largely on MM}

*46.E Light Waves and Their Uses. A. A. Michelson. (University of Chicago Press, Chicago, 1903), 166 pp. Describes his experiments to 1899. Note: Bibliographies for the various $M$ and MM experiments and discussions concerning them are given, e.g., in Whittaker (item 34); M. von Laue, Relativitätstheorie; Lecat, Bibliographie de la relativité; Jaffe (item 48).

47.E Studies in Optics. A. A. Mrchelson. (University of Chicago Press, Chicago, 1927), 176 pp. Contains quantitative descriptions of experiments.

48.E Michelson and the Speed of Light. Bernard JAFFe. (Anchor Books, Doubleday and Company, New York, 1960). Describes the experiments qualitatively. Bibliographies.

49.E The Principle of Relativity. E. Cunningham. (Cambridge University Press, New York, 1914), Chapter 2, pp. 15-20. Consideration of reflection of light at a moving mirror in MM experiment. Same material in Cunningham, Relativity and the Electron Theory (Longmans Green and Company, London, 1915), pp. 16-20. More sophisticated treatments in Silberstein (item 39) and in references given there.

50.I Die Physik 1914-1926. O. D. Chwolson. (F. Vieweg und Sohn, Braunschweig, Germany, 1927), Chapter 16, "Der neue Versuch von Michelson (1925)." Detailed description and analysis.

51.I "Conference on the Michelson-Morley Experiment." Astrophys. J. 68; 341-402 (1928). A general examination of methods employed and results obtained. Contributions by Michelson, Lorentz, Miller, Kennedy, Hedrick, Epstein, and Bateman. Also a discussion.

*52.E "Ether-Drift Experiments and the Determination of the Absolute Motion of the Earth." D. C. Miller. Revs. Modern Phys. 5, 203-242 (1933). A good fullscale review, with photographs of equipment, bibliography, etc.

53.A "New Analysis of the Interferometer Observations of Dayton C. Miller." R. S. ShankLand, S. W. McCuskey, F. C. Leone, and G. Kuerti. Revs. Modern Phys. 27, 167-178 (1955). The famous case study on the effects of small experimental uncertainties; still reads like a fine detective story.

54.I “A New Aether-Drift Experiment." L. Essen. Nature 175, 793-794 (1955). A fairly rough MM experiment using microwaves (9200 Mcs).

Note: See also items : 1 (Lorentz on $\mathrm{M}$ experiment, pp. 1-7), 25, 34 (Vol. I, 390-2, 404-5), 49, 39, 43, 44, $45,28$.

\section{Variation of Electron Mass with Velocity}

55.E Lectures on Theoretical Physics. H. A. LoRentz. (Macmillan, London, 1931), Vol. III, Chapter 7, pp. 269-288. "Experimental Investigations on the Mass of the Electron." On Kaufmann, Bestelmeyer, Bucherer, Neumann, Guye, and Lavanchy, with data and descriptions. For more recent, briefer survey of this ground, see item 36.

56.E Elements of Modern Physics. PaUl L. CopeLAND and William E. Bennett. ' (Oxford University Press, New York, 1961), pp. 60-72, "Experimental Verifications of the Equivalence of Mass and Energy," contains detailed description of Perry and Chaffee experiment on $e / m$ for electrons by time-offlight measurement.

57.I "Messungen der Massenveränderlichkeit des Elektrons an schnellen Kathodenstrahlen." M. Nacken. Ann. Physik 23, 313-329 (1935). Electron beam accelerated to nearly $0.7 \mathrm{c}$.

58.E "A Determination of the Masses and Velocities of Three Ra-B Beta-Particles." M. M. Rogers, A. W. McReynolds, and F. T. Rogers, JR. Phys. Rev. 57, 379-383 (1940). Check of relativistic formula to speeds up to $0.75 c$, to distinguish between Abraham and Lorentz models of electron.

59.I "Review of the Experimental Evidence for the Law of Variation of the Electron Mass with Velocity." P. S. Faragó and L. JÁnossy. Nuovo cimento (Series 10) 5, 1411-1436 (1957). An extensive and skeptical review of main experiments to that date. See also letter by Champion, Nuovo cimento 7, 122 (1958); and counterargument, Raboy and Trail, Nuovo cimento 10, 797-803 (1958).

Useful graphs giving values of $m / m_{0}$ and $\beta$ versus accelerating potential are given in $\mathrm{S}$. Dushman, "Mass-Energy Relation," Gen. Elec. Rev. 47, 6-13 (1944)

Note: See also theoretical papers in Section VI below.

\section{E. Some Other Representative Experiments}

*60.I “New Experimental Tests of Special Relativity." J. P. Cedarholm, G. F. Bland, B. L. Havens, And C. H. Townes. Phys. Rev. Letters 1, 342-343 (1958). Comparison of frequencies of two masers having their beams of $\mathrm{NH}_{3}$ molecules travel in opposite directions; result is that "ether drift" would have to be below $10^{-1}$ of earth's orbital velocity. [The effect is of first order in velocity of laboratory with respect to the ether. Theory in C. Møller, Suppl. Nuovo cimento 6, 381-398 (1957).]

61.I “Nuclear Dynamics, Experimental." M. StanLeY Livingston and Hans A. Bethe. Revs. Modern Phys. 9, 245-390 (1937). While most of the experimental data and procedures have, of course, since been improved (e.g., see K. T. Bainbridge, in E. Segré, editor, Experimental Nuclear Physics, Vol. I), this historically valuable article gives full references and, for example, comparisons of calculated and experimental $Q$ values.

For earliest good application of SRT to data on nuclear disintegration, see discussion of CockcroftWalton experiment by K. T. Bainbridge, "The Equivalence of Mass and Energy," Phys. Rev. 44, 123 
(1933). See also Oliphant, Kinsey, and Rutherford, Proc. Roy. Soc. 141, 722-733 (1933).

62.A "Precision Measurement of the Wave-Length and Spectral Profile of Annihilation Radiation

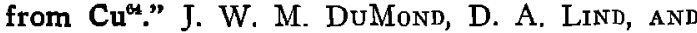
B. B. Watson. Phys. Rev. 75, 1226-1239 (1949). As an example of a thorough experimental project; full description of method and equipment.

63.A "Summary of Recent Measurements of the Compton Effect." A. Bernstein and A. K. Mann. Am: J. Phys. 24, 445-450 (1956). Review of experimental work, with layouts and data.

Note: For experiments involving time dilation, see Sec. VII below.

\section{MORE ON INERTIA OF ENERGY}

*64.E The Concept of Mass in Classical and Modern Physics. Max Jammer. (Harvard University Press, Cambridge, Massachusetts, 1961), 230 pp., Chapter 13. "Mass and Energy" is an excellent, fully documented review of the field from Maxwell on. Includes discussion of Einstein's 1905 paper (item 1) on inertia of energy, and its circular reasoning.

Note: For other articles by Einstein on mass-energy equivalence in SRT, see Ann. Physik 20, 627-633 (1906) ; 23, 371-384 (1907) ; Bull. Am. Math. Soc. 41, 223-230 (1935).

65.E "Derivation of the Mass-Energy Relation." $\mathrm{H}$. E. Ives. J. Opt. Soc. Am. 42, 540-543 (1952). Intends to show that Einstein "did not derive the massenergy relation" in 1905, and that the credit goes to Poincaré and Hasenöhrl. A better example of a small but vocal tradition.

*66.E The Theory of the Relativity of Motion. R. C. Tolman. (University of California Press, Berkeley, 1917), 225 pp. Derivation of $E=m c^{2}$ by collision of particles, pp. 35-41. Originated in article by Lewis and Tolman, Phil. Mag. 18, 510-523 (1909). Essentially the same treatment is in R. C. Tolman, Relativity, Thermodynamics and Cosmology, pp. 43-50, and many recent books.

*67.E Introduction to Atomic and Nuclear Physics. Otro Oldenberg. (McGraw-Hill Book Company, Inc., New York, 1961), 3rd ed., 380 pp. Appendix 7, pp. 362-364, has the photon-in-a-box derivation of $E=m c^{2}$, based on Max Born (item 4), and should be read together with a critique and extension of the method by Eugene Feenberg, "The Inertia of Energy." Am. J. Phys. 28, 565-566, 1960.

68.I "Masse und Energie in der speziellen Relativitätstheorie." R. Lämmel. Helv. Phys. Acta 12, 511-518 (1939). Uses Minkowskian representation for motion of $c$. of $m$. of two spheres to derive usual result (without using velocity addition theorem or energy conservation theorem).

69.E "L'Inertie de l'énergie et ses conséquences." P. Langevin. J. phys. radium 3, 553 ff. (1913). Reprinted in Oeuvres scientifiques de Paul Langevin (CNRS, Paris, 1950), pp. 397-426. Review article with many examples. The same collection contains also reprints of two other review articles by Langevin in his characteristically clear and graceful style.

70.I "Zur Theorie der Raketen." J. ACKERET. Helv. Phys. Acta 19, 103-112 (1946). Relativistic motion of rocket with changing rest mass. A thorough and useful review, with examples. On the same general problem, see "Relativistic Mechanics of a Material Point of Variable Mass." N. S. Kalitsin, Soviet Phys. -JEPT 1, 565-567 (1955). Minkowskian analysis.

71.I "Special Relativity and the Electron." W. W. Harman. Proc. IRE 37, 1308-1314 (1949). A straightforward discussion of the modification of laws and techniques in engineering practice involving electrons at high speed.

72.I "Wave and Inertial Properties of Matter." RICHARd Schlegel. Am. J. Phys. 22, 77-82 (1954). Inertial properties of matter and mass-energy equivalence are derived from de Broglie equation, LT, and $E=h \nu$.

73.A "Relativistic Mechanics of a Particle." David PARK. Am. J. Phys. 27, 311-313 (1959). Axiomatic development, to parallel Newtonian mechanics.

\section{TIME DILATION AND CLOCK PROBLEMS}

From the earliest days of SRT, much attention has been paid to time dilation and the clock problem, or twin "paradox," or "voyageur de Langevin." By now, far too much seems to have been written on this. But students are intrigued by it as much as ever, and if the discussion is kept in bounds, it can serve a useful function.

74.I "Experimental Study of the Rate of a Moving Clock." H. E. Ives and G. R. Strlwell. J. Opt. Soc. Am. 28, 215-226 (1938). The basic paper includes clear photos and drawings. See also criticism by R. C. Jones, J. Opt. Soc. Am. 29, 337-339 (1939) ; reply by Ives and Stilwell, J. Opt. Soc. Am. 31, 369-374 (1941) ; repetition of original experiment by G. Otting, Physik Z. 40, 681-687 (1939); and summary of history of idea of rate dependence on speed, by H. E. Ives, J. Opt. Soc. Am. 37, 810-813 (1947).

*75.I "Variation of the Rate of Decay of Mesotrons with Momentum." BRuno Rossi and D. B. Hall. Phys. Rev. 59, 223-228 (1941). Experimental check of time dilation via the dependence of lifetime of cosmic ray mesons on their energy. For artificially produced mesons, an early check was by R. P. Durbin, H. H. Loar, and W. W. Havens, Jr., "The Lifetimes of the $\pi^{+}$and $\pi^{-}$Mesons," Phys. Rev. 88, 179183 (1952). See also summary by F. S. Crawford, Jr. (item 79).

76.I "Some Recent Experimental Tests of the Clock Paradox." C. W. Sherwin. Phys. Rev. 120, 17-21 (1960). Discusses work of Pound-Rebka and of HaySchiffer-Cranshaw-Egelstaff as experimental verification of velocity dependence of clock rates.

*77.E "The Space Traveller's Youth." H. Bondi. Discovery 18, 505-510 (1957). For general reader, but 
with worked-out examples and Minkowskian diagrams. Elaborated by M. Born, Phys. Blätt. 14, 207-212 (1958).

*78.E "The Clock Paradox." G. Builder. Australian J. Phys. 10, 226-245 (1957). Uses only SRT, avoids the "paradox" by proper choice of method of calculating retardation. See also G. Builder, "The Resolution of the Clock Paradox," Phil. Sci. 26, 135-144 (1959).

*79.E "Experimental Verification of the "Clock Paradox' of Relativity." F. S. CRAWFORd, JR. Nature 179, 35-36 (1957). Summarizes experiments on mesons by Rossi, Hilbert, and Hoag (1940), F, Rasetti (1941), P. M. S. Blackett (1937), and H. Ticho (1947), which, together, verify time dilation. [Reply by H. Dingle, Nature 179, 865-866 (1957) is followed by rejoinder by F. S. Crawford, Nature 179 , 1071-1072 (1957).] Best read together with item 84 .

*80.E "The Clock Paradox in Relativity." C. G. DARwIN. Nature 180, 976-977 (1957). A very simple discussion, showing asymmetry in logs kept by two space ships counting, each other's regularly sent light flashes.

81.E “Time Dilation and Doppler Effect." J. D. RoBInson and E. Fennberg. Am. J. Phys. 25, 490 (1957). Uses relativistic formula for longitudinal Doppler effect. See also E. Feenberg, Am. J. Phys. 27, 290 (1959).

82.E "Twin Paradox in Special Relativity." RoBerT H. Romer. Am. J. Phys. 27, 131-135 (1959). Uses only simplest concepts of SRT, small velocities, and virtually no mathematics. Discusses some of the usual objections.

*83.E "Relativity and Space Travel." J. R. Pierce. Proc. IRE 47, 1053-1061 (1959). Discusses quantitatively a clock paradox, a twin problem, frequency shift in gravitational field, clock rate on satellite, speed allowable by photon rocket, and insufficiency of interstellar matter to power a space ship. See also C. Darwin, item 80 .

*84.I “The 'Clock Paradox' and Space Travel.” E. M. McMillan. Science 126, 381-384 (1957). Uses SRT and ordinary case as well as continuously accelerated coordinate system. Examples to show that "relativistic time modifications are negligible for travel within solar system" even for large accelerations, and that necessary energy expenditures to get important effect is "far beyond any foreseeable practical limits."

*85.I "Relativistic Observations and the Clock Problem." J. Terrell. Nuovo cimento 16, 457-468 (1960). Perhaps the best of the recent reviews. Shows from several points of view where asymmetry lies. Only SRT involved. Good bibliography.

*86.I “On Solutions of the Clock Paradox.” G. D. ScotT. Am. J. Phys. 27, 580-584 (1959). A useful, brief survey of discussions via length contraction, Doppler effect, and world lines in chronogeometry; repeats that GRT adds no physically new aspect.

87.I "The Clock Paradox." C. C. MAcDuffeE. Science 129, 1359 (1959). Time dilation treated in two- dimensional Minkowski space. Made even simpler in M. L. Boas, Science 130, 1471-1472 (1959).

88.I "Certain Matters in Relation to the Restricted Theory of Relativity, with Special Reference to the Clock Paradox and the Paradox of the Identical Twins." W. F. G. Swann. Am. J. Phys. 28, $55-64,319-323$ (1960). Part I is a thoughtful study of "Fundamentals," Part II on the clock paradox.

89.I Electromagnetism and Relativity. E. G. CuLLwICK. (Longmans Green and Company, London and New York, 1957), 299 pp. Chapter 5, pp. 62-80 and Appendix 2 on clock paradox, partial to Dingle's view.

90.A “Zum Uhrenparadoxon." M. BORN AND W. BIEM. Proc. Konink1. Ned. Acad. Wetenschap. B61, 110-120 (1957). Approach via GRT and by simplification of solution in C. Mфller, Theory of Relativity (1952). Another GRT treatment, generally considered also among the best, is by $R$. C. Tolman, Relativity, Thermodynamics, and Cosmology (1934), pp. 192197.

Note: Several of the books cited above have good treatments of time dilation and clock problem, e.g., Arzeliès (item 2), Born (item 4), Sherwin (item 25), Stephenson and Kilmister (item 11), and Pauli (item 8).

There has been recently a well-known debate on the twin "paradox" For those who are interested in the points ex "paradox-" For those who are changed among the main discussants, this fairly complete chronological listing will be helpful: W. H. McCrea, Nature 167, 680 (1951): G. Thomson, The Foreseeable Future (Cambridge University Press, New York, 1955), pp. 88-89; C. Dingle, Nature 17\%, 782 (1956); H. Dingle Nature 178 Crea, Nature 177, 784-785 (1956); H. Dingle, Nature 178, (1956) H. Dingle, Proc. Phys. Soc. (London) A69, 925 (1956) (1956) Dingle, Proc. Phys. Soc. (London) A69, 925 A69, 935 (1956); F. S. Crawford, Jr., Nature 179, 35-36 (1957): H Dingle Nature 179, 865-866 (1957)- W H McCrea Nature 179, 909-910 (1957): F. S. Ćrawford J. Nature 179 1071-1072 (1957); H. Dingle Nature 179 1242-1243 (1957): J. H. Fremlin Nature 180, 499-500 (1957); H. Dingle, Nature 180, 50́ (1957); E. M. McMillan, Science 126, 381-384 (1957) : G. Builder, Australian J. Phys. 10, 226-245 (1957); H. Dingle, Australian J. Phys. 10 418-423 (1957); G. Builder, Australian J. Phys. 10, 424-428 (1957); C. Darwin, Nature 180, 976977 (1957); L. Essen, Nature 180, 1061-1062 (1957); H Dingle, Nature 180, 1275-1276 (1957); R. Fisher and W. H. MeCrea, Discovery 18, 56-58 (1957); Lord Halsbury et al. Discovery 18, 174-175 (1957); H. Bondi, Discovery 18, 505-510 (1957); R. M. Frye and V. H. Brigham, Am. J. Phys. 25, 553-555 (1957); H. Dingle, Science 127, 158160 (1958); and E. M. McMillan, Science 127, 160-162 (1958).

Since then the papers on this subject bave tended less to be a debate involving Dingle; further bibliography to 1960 is given in footnotes 16 to 23 of item 85 (Terrell).

There also was an earlier exchange of articles on the concept of time among $\mathbf{H}$. Dingle, $\mathbf{P}$. S. Epstein, and $\mathbf{L}$ Infeld, in Am. J. Phys. 10 (1942) and 11 (1943).

\section{SOME OTHER CONGEQUENCES OF LT} (E.G., VISUAL APPEARANCE)

*91.I "Invisibility of the Lorentz Contraction." James Terrell. Phys. Rev. 116, 1041-1045 (1959). It is shown-not without embarrassment to some of us-that to a single observer objects in rapid motion at a relatively large distance appear to have undergone rotation, not contraction. See also earlier paper for case of spheres by $R$. Penrose, Proc. Cambridge Phil. Soc. 55, 137-139 (1959). 
*92.E “The Visual Appearance of Rapidly Moving Objects." V. F. Weisskopf. Phys. Today 13, 24-27 (1960). A beautiful summary of the work of J. Terrell (see item 91) and its implications.

93.E "Observation of Length by a Single Observer." Roy Weinstein. Am. J. Phys. 28, 607-610 (1960). On the length seen by a single observer: close to the trajectory of a rod the latter can appear elongated. However, for display of contraction by use of pulsed radar system, see C. W. Sherwin, Am. J. Phys. 29, 67-69 (1961). For case of nearby spheres and rods, see "Apparent Shape of Large Objects at Relativistic Speeds," Mary L. Boas, Am. J. Phys. 29, 283-286 (1961). For early work on appearance of objects, see also "The FitzGerald-Lorentz Contraction-Some Paradoxes and Their Resolution," W. H. McCrea, Sci. Proc. Roy. Dublin Soc. 26, 27-36 (1952). For extension of argument to measurement of time intervals by single observer, see A. D. Crowell, Am. J. Phys. 29, 370-371 (1961).

94.I "Note on the Stress Effects Due to Relativistic Contraction." E. Dewan and M. Beran. Am. J. Phys. 27, 517-518 (1959). A nice teaser. Will a thread between two identical rockets break as they leave at identical velocity, one behind the other? See also discussion of this article by A. A. Evett and R. W. Wangsness, Am. J. Phys. 28, 566 (1960). Another pazzle (will a length-contracted object fall through a grid over which it slides?) is in W. Rindler, Am. J. Phys. 29, 365-366, 859 (1961).

95.I "Relativity of Moving Circuits and Magnets." David L. Wenster. Am. J. Phys. 29, 262-268 (1961). A necessary reminder that even for slow motions, the L.T giving charge density cannot be approximated nonrelativistically. Illustrative examples for rotating and nonrotating circuits and magnets.

96.A "Lorentz Transformation and the Thomas Precession." W. H. Furry. Am. J. Phys. 23, 517-525 (1955). Kinematic effects of SRT treated by considering iterations of the infinitesimal LT.

\section{OTHER TEAChING AIDS}

\section{A. Laboratory and Demonstration Experiments}

Almost nothing directly applicable to teaching SRT is now available, and very little that is indirectly applicable. But there is hope for early help with apparatus.

97. Speed of Light. Rotating mirror method, apparatus by Leybold Nachfolger, distributed in the U. S. by J. Klinger and others. Model 47640, $\$ 125$ (plus $\$ 85$ for optional attachments 31109, 46012a, 46320). For Kerr Cell shutter method, see C. H. Palmer, Jr., and G. S. Spratt, "A Laboratory Experiment on the Velocity of Light," Am. J. Phys. 22, 481-485 (1954). See also W. P. Alford and A. Gold, Am. J. Phys. 26, 481-484 (1958).

98. Michelson Interferometer. See T. B. Brown, editor, The Lloyd William Taylor Manual of Advanced
Undergraduate Experiments in Physics. (AddisonWesley Publishing Company, Inc., Reading, Massachusetts, 1959), pp. 227-230. A commercial model ("M4 Interferometer") is sold by Atomic Laboratories, Inc., Berkeley, California. Model 87481-1 with Michelson Optics, $\$ 250$; Model 87481-2 with FabryPerot Optics, $\$ 275$; Model $87481-3$ with both Optics, $\$ 395$; Model 71859-26 Mercury Light Source, $\$ 15$.

An inexpensive Michelson Interferometer is described by E. C. Cave and L, V. Holroyd, Am. J. Phys. 23, 61-63 (1955).

For microwave version of Michelson interferometer, see T. B. Brown, manual listed above, pp. 298-299; also T. G. Bullen, Am. J. Phys. 24, 525-526 (1956) A $3-\mathrm{cm}$ microwave apparatus is available from Welch Scientific Company, Chicago, Model 2640, $\$ 385$.

An inexpensive optical interferometer experiment is under design at the MIT Science Teaching Center (directed by F. L. Friedman), and another at Educational Services Incorporated (E.S.I., directed by $\mathrm{U}$. Haber-Schaim), where there is also work on. a first-order (null) ether-drift experiment and an acoustical Fizeau experiment analogue.

99. Electron Dynamics at High Speeds. See M. Peter, "Lecture Demonstration of Relativistic Behavior of Electrons," Am. J. Phys. 23, 515-517 (1955).

V. Neher at California Institute of Technology is developing a Busch tube experiment for student laboratory. A number of projects are under way at the Science Teaching Center of M.I.T., involving Professors Frisch, Bertozzi, King, and Smith; they include experiments on limiting velocity of electrons in linear accelerator, time-of-flight measurement of electron beam, and a simplified Bucherer-Kaufmann apparatus. Some experiments are to be on film; others also are intended to yield apparatus for students.

The use of beta-ray spectrometers for student laboratories is described in T. B. Brown (item 98), pp. 499-505; by C. M. Fowler and R. Dean Dragsdorf, Am. J. Phys. 23, 108-210 (1955); in Experiment A-6, Supplement to Analytical Laboratory Physics, by H. F. Meiners, W. Eppenstein, K. H. Moore, and J. P. Nickol, Rensselaer Polytechnic Institute.

A commercial beta-ray spectrometer is sold by Atomic Laboratories, Inc., Model 79652, \$295; it requires also Electromagnet Model 79641, \$295, and scaler, PSU, vacuum pump, and gauge.

\section{B. Films}

Here again, virtually nothing is yet on the market specifically for teaching SRT. The nearest is the 26minute film "Frames of Reference" (1958), produced by PSSC-ESI and distributed by Modern Talking Picture Service, Inc., 3 East 54 Street, New York 22, New York. Two filmed 50-minute lectures on SRT by G. Gamow are soon to be released by General Dynamics-Convair, San Diego, California. 